Submitted to J. Phys. Oceanogr., January 2, 2003.

\title{
Broadly Distributed and Locally Enhanced Turbulent Mixing in a Tidal Estuary
}

\author{
Hartmut Peters \\ Rosenstiel School of Marine and Atmospheric Science, University of Miami, Miami, Florida
}

\begin{abstract}
Spatial variations of vertical turbulent mixing along a stretch of the Hudson River estuary are examined with focus on the vicinity of a "hydraulic control point" at the George Washington Bridge, where the cross section narrows and the thalweg takes a bend. Richardson numbers are lowered and mixing is enhanced downstream of this "modest" morphological feature, qualitatively following predictions based on hydraulic theory by Chant and Wilson (2000). The enhancement in the viscous dissipation rate, $\varepsilon$, is only a modest factor of $2-3$, however, extending over $\sim 2 \mathrm{~km}$ along the river. Upon averaging over tidal and fortnightly cycles and multiple cruises, streamwise variations of $\varepsilon$ along the probed $\sim 15 \mathrm{~km}$ stretch of the estuary are surprisingly small given that individual depth-averages of $\varepsilon$ across the halocline vary by over 3 orders of magnitude. The principal result is that the observed part of the Hudson River showed strong broadly distributed mixing everywhere with little local concentration.
\end{abstract}

\section{Introduction}

The beginnings of estuarine theory in the 1950s encompass concepts of hydraulic control in two-layer flow (Stommel and Farmer, 1952, 1953) as well as concepts of spatially distributed mixing with a viscous-advectivediffusive balance (VAD) in continuously stratified flows (e.g., Pritchard, 1952, 1954, 1956; Rattray and Hansen, 1962; Hansen and Rattray,1965). These two approaches are not necessarily mutually exclusive considering that Stommel and Farmer (1953) assumed a "control" at the mouth of estuaries with various degrees of unspecified mixing well inside of that mouth. Pritchard (1952 etc.) and Rattray and Hansen (1962), in contrast, were concerned with exactly the latter, flow dynamics related to mixing within the estuary, especially within the "central regime" of the salt intrusion.

Conceptually, hydraulics and VAD are incompatible, hydraulic theory being nonlinear, inviscid and nonmixing, and VAD theories neglecting nonlinearity. Recently, however, Winters and Seim (2000) and Hogg et al. (2001) have shown how the real world falls into the continuum between pure hydraulics and pure VAD concepts, how mixing modifies processes near hydraulic controls, and how, for example in the Strait of Gibraltar mixed waters carry a substantial part of the total transport. And, in some contradiction to the basic tenets of hydraulics, the vicinity of hydraulic control points has long since been probed for locally enhanced mixing. One prominent example is Wesson and Gregg's (1994) field experiment in the Strait of Gibraltar. Hydraulic jumps are often assumed to be associated with intense mixing. However, less violent aspects of hydraulics may also lead to enhanced mixing as argued by Chant and Wilson (2000) for the case of the Hudson River. They show that, downstream of a constriction at the George Washington Bridge in New York City, the vertical structure of the flow should, and indeed does, change in response to hydraulic constraints such that gradient Richardson numbers are lowered on average. Their conclusion that turbulent mixing should be enhanced at this location is examined herein.

In a series of field experiments in the Hudson River estuary in 1994-95 VAD-type concepts were probed for their realism in analyzes of integral momentum and mass budgets (Geyer et al., 2000), of near-bottom turbulence (Trowbridge et al., 1999), and mixing across the halocline (Peters and Bokhorst, 2000, 2001). The observations were carried out in a fairly straight and uniform section of the estuary in a deliberate effort to avoid 
complications associated with bathymetric variations. The study demonstrated vigorous mixing related to the tidal stirring outside of morphologically variable areas. Other "partially mixed" estuaries, the Fraser River of British Columbia (Geyer and Smith, 1987) and Suisun Cutoff of San Francisco Bay (Stacey et al. (1999) also show broadly distributed mixing unrelated to bathymetrical features.

Considering such spatially distributed mixing on the one hand, and, on the other hand, that natural estuaries inevitably contain morphological features favorable to hydraulic control processes and other highly nonlinear flow phenomena, one may ask how locally concentrated or spatially distributed vertical mixing is in estuarine flow. Naturally, the answer is different for each estuary. Puget Sound in the State of Washington, for example, a morphologically complex fjord, displays weak mixing in its deep basins, energetic mixing in its hydraulically controlled entrance, and a complete turning over of the stratification by transverse flows at the Tacoma Narrows during some tidal phases (Seim and Gregg (1994, 1997).

This paper is concerned with a morphologically and dynamically less complex and less dramatic setting, a part of the Hudson River which for the most part has a fairly uniform channel with embedded "modest" bathymetric variations. The papers addresses the question how much locally enhanced mixing, related to bathymetric features, contributes to the overall spatially averaged mixing.

The Hudson River is usually classified as a "partially mixed" estuary although instantaneous conditions vary from that of a salt wedge to well-mixed. Further characteristics of flow, stratification and mixing have been presented, e.g., by Peters (1999). A field experiment in the lower Hudson of May 2001 was specifically designed to investigate the question of broadly distributed versus locally enhanced mixing. These new observations are analyzed herein together with the measurements in the same general area from 1994-95 which extensively cover tidal, fortnightly and longer-term temporal variations of mixing. The 1994/95 microstructure observations have been analyzed by Peters $(1997,1999)$ and Peters and Bokhorst (2000, 2001), papers henceforth referred to as P97, P99, PB00, and PB01, respectively. Considering the pronounced tidal and fortnightly time variations of flow and mixing in tidal estuaries laid out in the above-referenced papers, the 2001 and 1994-95 together are probably the only current set of observations extensive enough to allow addressing the topic of spatial variability of turbulent mixing.
After outlining the 2001 measurements, their environmental conditions and the bathymetry in the following section, the basic result of this study, the alongestuary average dissipation rate, is presented in Section 3. The subsequent section probes how representative and significant that average is. A feature of enhanced mixing related to channel morphology is discussed in Section 5, which is followed by summary and conclusions.

\section{Observations}

\section{a. Measurements, Instrumentation}

Turbulent mixing, stratification and tidal flow were observed from May 17 to May 24, 2001, with initial tests on May 16. May 17, 2001, is yearday 137. A little over 900 "drops" with the Shallow Water Microstructure Profiler ("SWAMP," P97) were taken from below the North River Sewage Treatment Plant (NRSTP) in Manhattan to Yonkers (Figure 1a). The microstructure profiling was accompanied by acoustic Doppler current profiling (ADCP). The measurements were concentrated around the George Washington Bridge (GWB) because of prominent bathymetric variations in its vicinity (Figure 2). Extensions of the work farther upstream toward Yonkers undertaken on May 23-24 accompany a dye release study by Drs. Chant, Geyer and Houghton, a connection that will not be pursued herein.

In addition to the new May 2001 observations similar microstructure / ADCP measurements from 1994/95 are also utilized herein. As outlined in P99, over 6000 microstructure drops were taken mostly in a $4-\mathrm{km}$ stretch off Manhattan south of the NRSTP with one section extending to north of the GWB (Figure 1b).

The loosely tethered profiler SWAMP has a full SeaBird conductivity - temperature - depth (CTD) package in addition to two shear probes measuring velocity microstructure, a fast FP07 thermistor and a SeaBird dual-needle conductivity cell, measuring temperature and conductivity microstructure, respectively. The reduction and evaluation of the data is explained in $\mathrm{P} 97$ and $\mathrm{PB} 00$. The CTD sensors provide profiles of temperature $(T)$, salinity $(S)$, potential density $\left(\sigma_{\theta}\right)$ and buoyancy frequency $(N)$. The primary microstructure variable is the viscous dissipation rate $(\varepsilon)$. The micro-conductivity $(C)$ can be evaluated in terms of turbulent overturning scales (Thorpe, 1977), an approach not utilized herein.

The ADCP measurements add the horizontal velocity vector $(u, v)$, vertical shear $V_{z}=\sqrt{(\partial u / \partial z)^{2}+(\partial v / \partial z)^{2}}$, and, in combination 


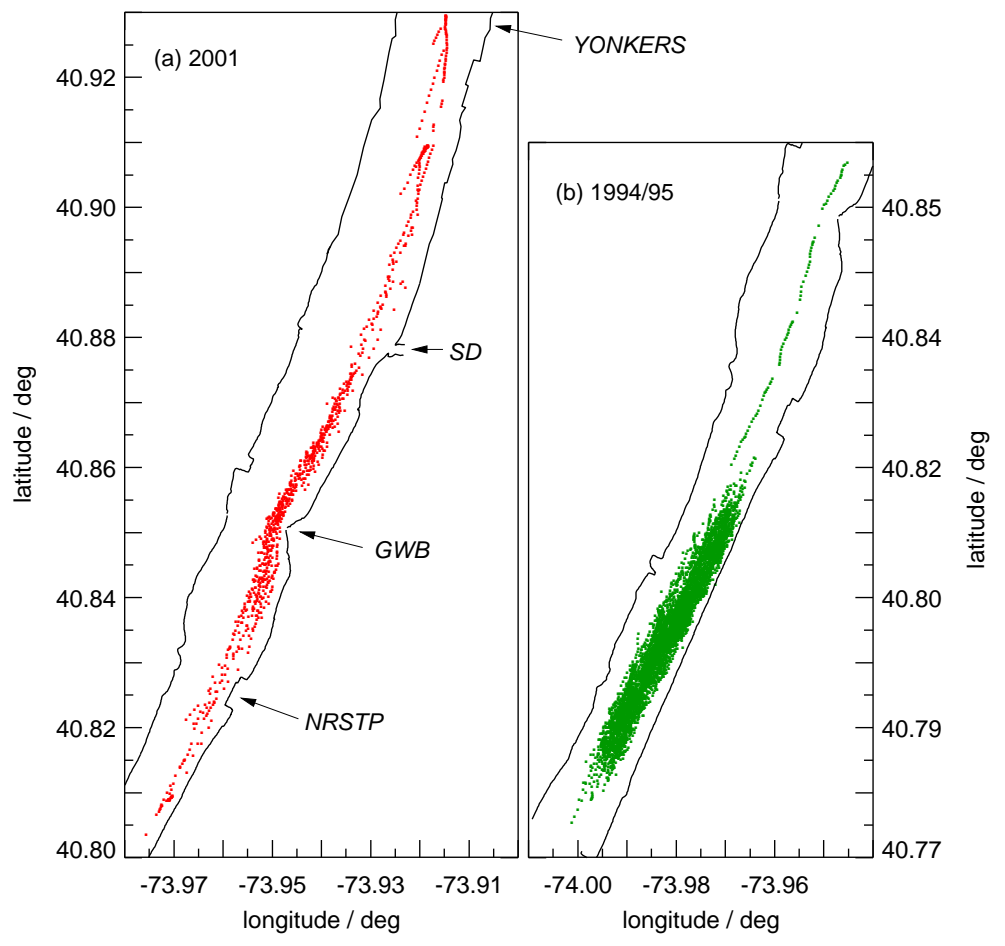

Figure 1. (a) Location of the microstructure drops of May 2001; (b) drops of 1994/95. Landmarks: NRSTP = North River Sewage Treatment Plant, GWB = George Washington Bridge, SD = Spuyten Duyvil.

with the CTD-derived $N$, the gradient Richardson number $R i=N^{2} / V_{z}^{2}$. PB01 explain how eddy diffusivity, eddy viscosity, turbulent stress and turbulent salt flux can be estimated from the combined SWAMPADCP data. An example set of microstructure / ADCP profiles is depicted in Figure 3.

\section{b. Tides and Other Environmental Factors}

This subsection briefly outlines environmental factors that affect the estuarine flow for the May 2001 observations. Corresponding information on the 1994/95 cruises can be found in P97 and P99. The 2001 cruise took place while the semidiurnal tidal amplitude of the sea surface at the Battery, Manhattan, was increasing from $0.5 \mathrm{~m}$ to $0.8 \mathrm{~m}$ within the fortnightly tidal cycle (Figure 4c). The maximum tidal amplitude was smaller than during some of the earlier cruises when maximum tidal amplitudes approached $1 \mathrm{~m}$ (P99). As explained in PB00 the water level measured at the Battery at the southern tip of Manhattan is interpreted in terms of slowly varying amplitude $\left(\zeta_{S D}\right)$ and phase $\left(\Phi_{S D}\right)$ by means of a complex demodulation that passes both the M2 and S2 tidal constituents.

The low-passed water level at the Battery was relatively constant during the observations, indicating an absence of major external forcing of the estuary by water level fluctuations in New York Bight. Such forcing can be important (PB00).

Figure $4 \mathrm{~d}-\mathrm{f}$ displays atmospheric conditions measured at Sandy Hook, New Jersey, about $40 \mathrm{~km}$ south of the observational area and on the shore of the Atlantic Ocean. Two low pressure systems passed through during the experiment as shown in the record of atmospheric pressure $\left(p_{a}\right)$, the first one being associated with fairly strong wind speeds $\left(V_{a}\right)$ of $8 \mathrm{~m} \mathrm{~s}^{-1}$ with stronger gusts. Otherwise wind speeds were moderate at a typical $5 \mathrm{~m} \mathrm{~s}^{-1}$. The measurements are only loosely indicative of winds over the Hudson River (i) because the cliffs, hills and highrise buildings along the river tend to strongly funnel the wind, and (ii) because inland winds tend to be more moderate than winds right at the coast. For the purposes of this paper it is only important that there were no major storms such that the action of the surface wind stress on the estuarine water column can be neglected as argued in PB00.

At the beginning and throughout the first half of the cruise the river flow at Green Island, $245 \mathrm{~km}$ upstream of the Battery in Manhattan, was unseasonably low with values of $50-250 \mathrm{~m}^{3} \mathrm{~s}^{-1}$. It reached values 

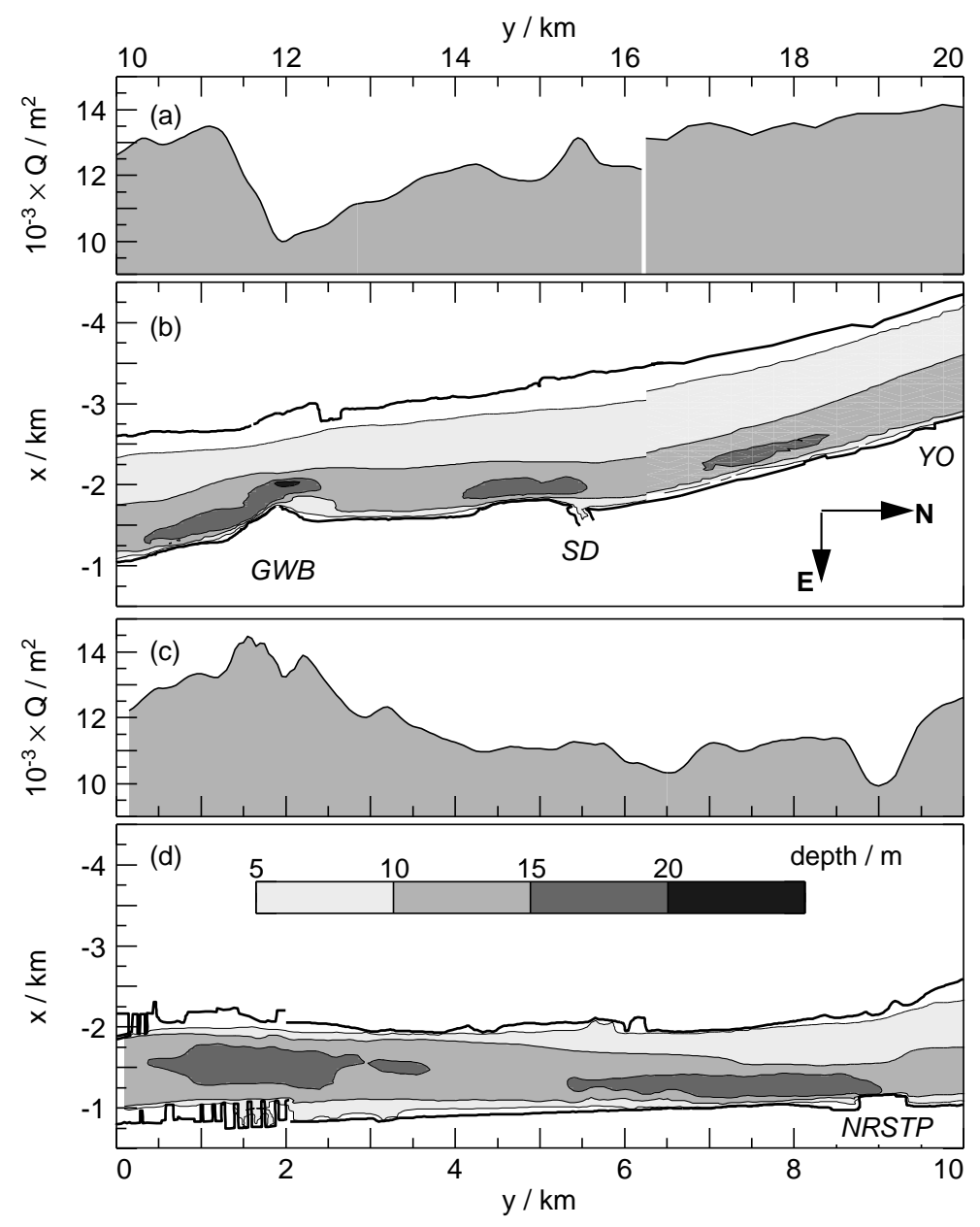

Figure 2. Bathymetry of the Hudson River between midtown Manhattan and Yonkers (YO). Cartesian coordinates $x$ and $y$ originate at $40.75^{\circ} \mathrm{N}, 74.00^{\circ} \mathrm{W}$, and are rotated $30^{\circ}$ clockwise to follow the direction of the river. Note the curvature of the thalweg near the George Washington Bridge and the change of cross section in its vicinity. See Fig. 1 for abbreviations. 


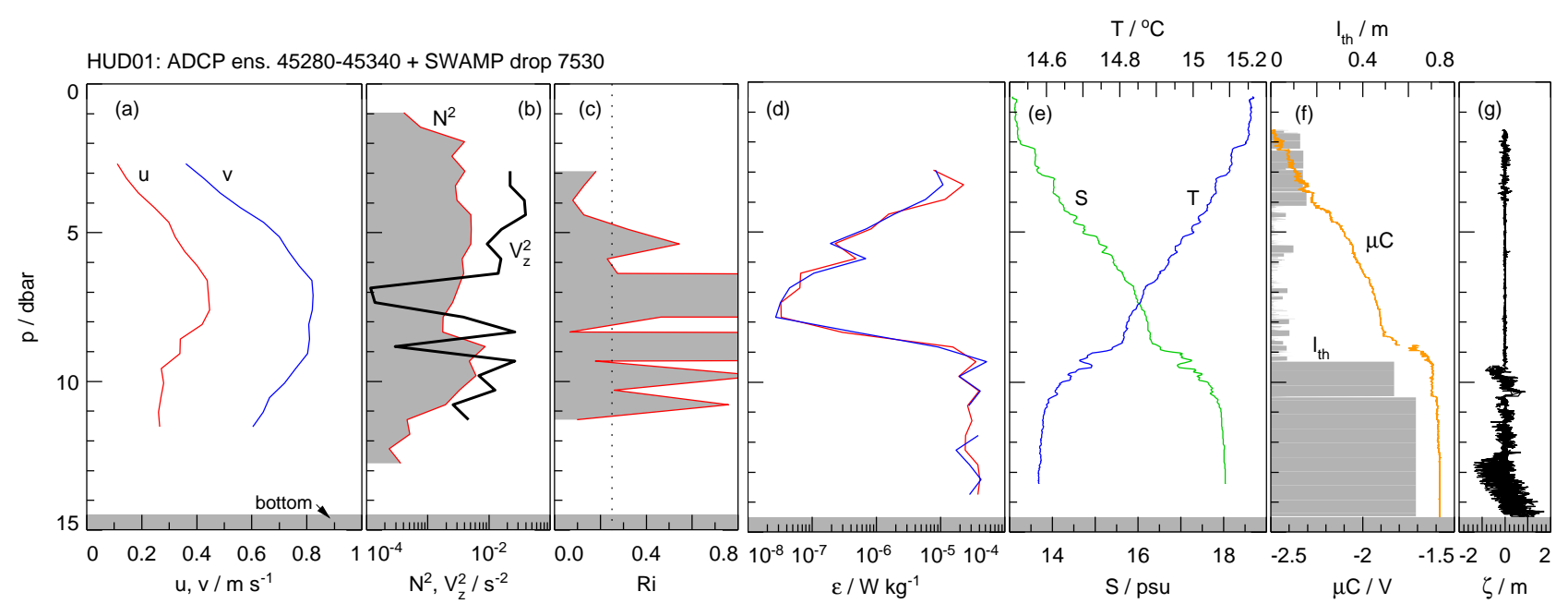

Figure 3. Example microstructure drop and associated ADCP measurements, drop \# 7530, 22 May 2001, 1214 UTC, $40^{\circ} 50.57^{\prime} \mathrm{N}, 73^{\circ} 57.22^{\prime} \mathrm{W}$. (a) Velocity profiles, (b) squared buoyancy frequency and squared shear, (c) Richardson number, (d) dissipation rate (2 channels), (e) salinity and temperature from CTD sensors, (f) raw microstructure conductivity and Thorpe scale, and (g) turbulent displacement.

more appropriate for the climatological spring freshet only at the end of the cruise. The low river flow implies that the stratification was probably somewhat stronger than normal (P99). This deviation from climatological means is only of minor concern for this study, however, because the basic patterns of mixing remain the same throughout strong variations of the river flow, and the associated variations of variables characterizing mixing, such es $\varepsilon$, remain modest as shown in P99.

\section{c. Bathymetry}

This paper explores flow processes related to variations in the channel morphology, and thus the bathymetry of the observational area needs to be explained. Depth contours and the channel cross section are depicted in Figure 2 in Cartesian coordinates that originate at $40^{\circ} 45^{\prime} \mathrm{N}, 74^{\circ} \mathrm{W}$ and are rotated $30^{\circ}$ clockwise to follow the general channel direction. Thus $y$ is the streamwise coordinate, and $x$ is in the spanwise direction. Typical channel depths are $15 \mathrm{~m}$ with maxima near $20 \mathrm{~m}$ just south of the George Washington Bridge (GWB) and the North River Sewage Treatment Plant (NRSTP). The width between the $10-\mathrm{m}$ isobaths varies from $0.4 \mathrm{~km}$ to $1.3 \mathrm{~km}$. The cross section, $Q$, is computed as integral of the water depth in the $x$-direction for simplicity. While maxima of $Q$ reach $14 \times 10^{3} \mathrm{~m}^{2}$, constrictions with $Q \approx 10 \times 10^{3} \mathrm{~m}^{2}$ are located at the GWB $\left(y=12 \mathrm{~km}\right.$, latitude $\left.40.75^{\circ}\right)$ and at the NRSTP $\left(y=9 \mathrm{~km}\right.$, latitude $\left.40.825^{\circ}\right)$. While the latter feature is minor, $Q$ expands by $35 \%$ in less than $1 \mathrm{~km}$ along the river going south from the GWB. In this stretch the thalweg turns significantly, giving rise to transverse flow as discussed by Chant and Wilson (1997).

Figure 2 displays a different source of bathymetric data north of $y=16.2 \mathrm{~km}$ than south of it, with different processing leading to jumps in isobaths and $Q(y)$. When comparing depths in Figure 2 with actual depths found during the measurements it has to be kept in mind that reference in the charts is mean lower low water, $0.76 \mathrm{~m}$ below the mean tidal level at the Battery (source: NOAA/NOS ${ }^{1}$ ). The actual cross section of the river is thus larger than shown in Figure 2a,c by up to about $2000 \mathrm{~m}^{2}$ depending on location and tide. The cross section was determined along the $x$-axis of the rotated coordinates, not perpendicular to the river axis. The limited accuracy of $Q(y)$ is of no consequence for this study.

\section{Streamwise Average of $\varepsilon$}

It is rather straightforward to compute average dissipation rates along the Hudson River from the combined 2001 and 1994-95 observations. Thereafter, considerable effort is needed to examine the statistical significance of this average. We begin with simply presenting the data. Figure 5 depicts the mean of $\varepsilon$ in

\footnotetext{
${ }^{1}$ See http://co-ops.nos.noaa.gov/benchmarks/8518750.html.
} 


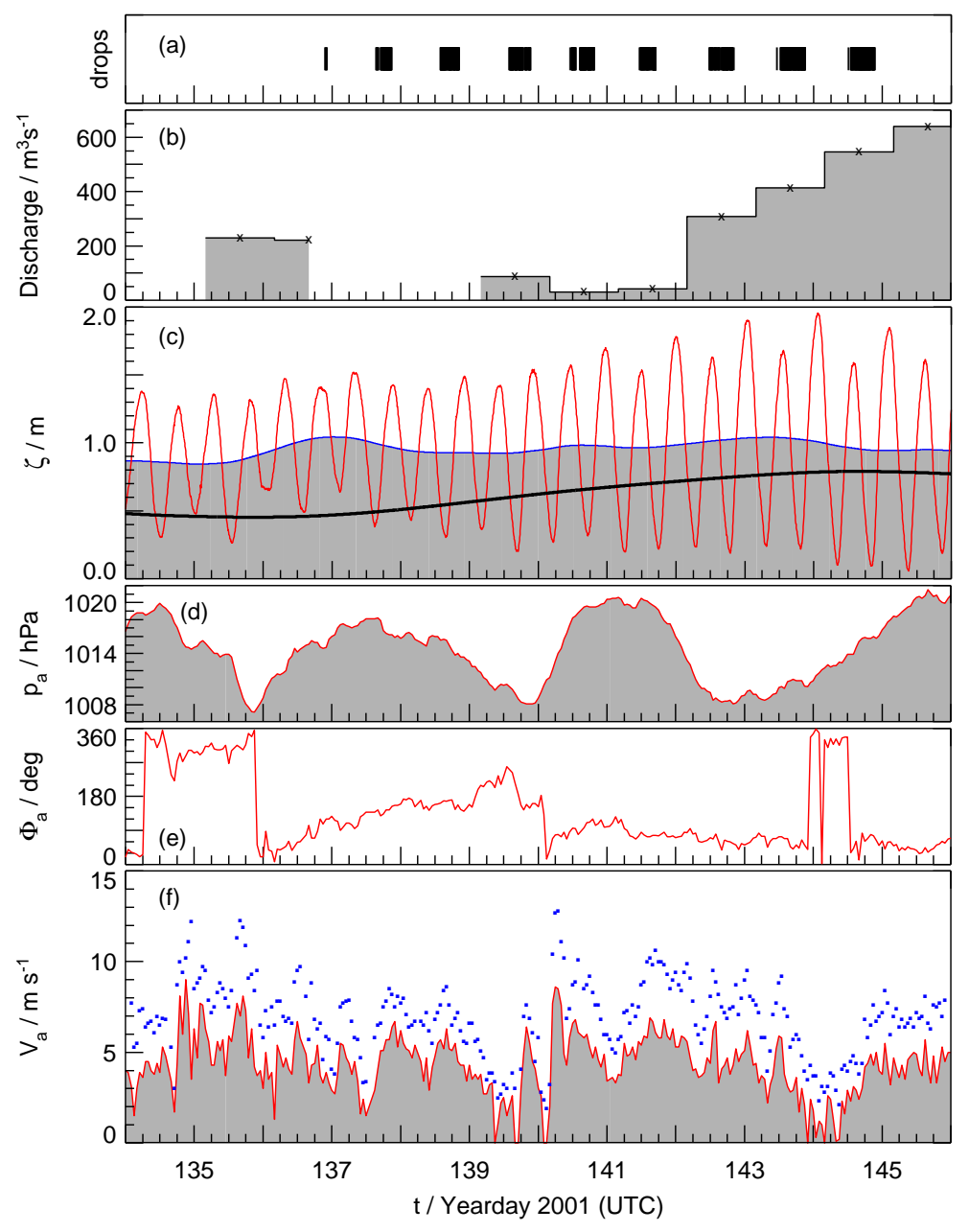

Figure 4. Environmental conditions during the experiment as function of time. (a) Microstructure drops. (b) River discharge at Green Island near Albany, New York. (c) Water level at the Battery, Manhattan (solid line), low-passed water level (shaded), and semidiurnal tidal amplitude (thick line). (d) Atmospheric pressure, (e) wind direction, and (f) wind speed at Sandy Hook. Dots indicate gust speeds. 


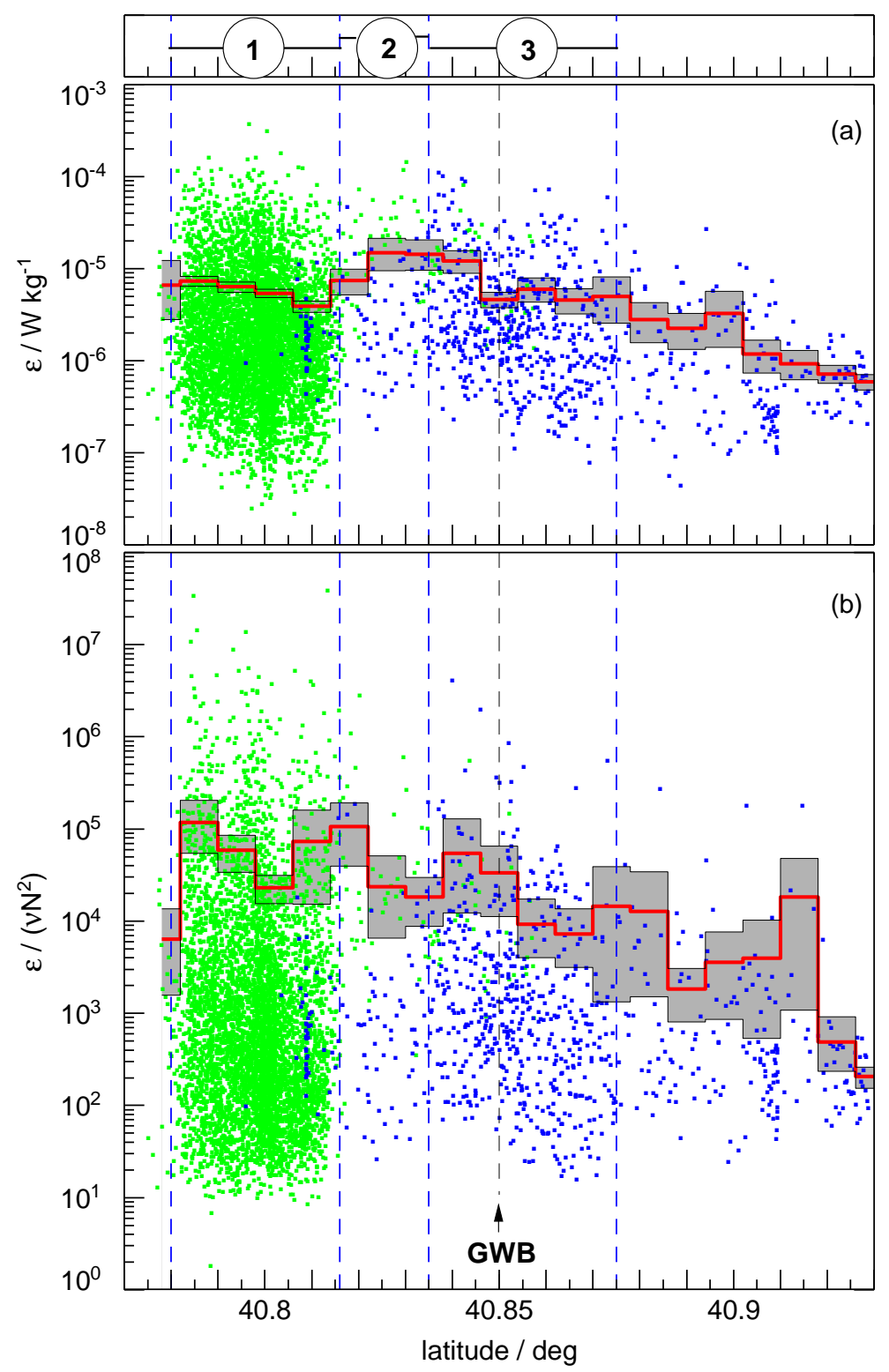

Figure 5. "Halocline" average (a) dissipation rate and (b) buoyancy Reynolds number as function of latitude; dots: individual microstructure drops; lines: mean in latitude bin with $97 \%$ bootstrap confidence limits shaded. Latitude bands $1-3$ are addressed in the text. 
bins of latitude along with their confidence bounds as well as individual drop data of $\varepsilon$. The figure further depicts the buoyancy Reynolds number as an alternative, nondimensional measure of mixing. With the kinematic viscosity $\nu$, the buoyancy Reynolds number is $R e_{b}=\varepsilon\left(\nu N^{2}\right)^{-1}$. See, e.g., Peters et al. (1995) for a discussion of $R e_{b}$. The drop data are averages from a normalized depth range of $0.45 \leq z / H \leq 0.75$, where $z$ is height above bottom and $H$ is the local water depth. At a typical water depth of $15 \mathrm{~m}$, this corresponds to a range from $6.75 \mathrm{~m}$ above the bottom to $3.75 \mathrm{~m}$ below the surface. This range mostly excludes the bottom and surface boundary layers (see also P99) and includes the estuarine halocline such that we refer to these data as "halocline averages." The halocline averages are further averaged in latitude bins with confidence bounds found from bootstrapping ( Efron and Gong, 1983).

In the river section with good data coverage, latitudes from $40.78^{\circ} \mathrm{N}$ to $40.875^{\circ} \mathrm{N}$, average $\varepsilon$ varied surprisingly little between $4 \times 10^{-6}$ and $1.5 \times 10^{-5} \mathrm{~W} \mathrm{~kg}^{-1}$ (Figure 5a). Further north, with sparse data coverage, the observed $\varepsilon$ decreased to slightly below $10^{-6} \mathrm{~W} \mathrm{~kg}^{-1}$. Bootstrap confidence bounds are tight, at most a factor of 2 , and often much smaller. This has to be viewed on the background of individual drop halocline average $\varepsilon$ spanning 3-4 decades of variability. The maximum average $\varepsilon$ occurred at latitudes $40.82^{\circ} \mathrm{N}-40.845^{\circ} \mathrm{N}$ south of the George Washington Bridge. This maximum is significant with respect to the confidence bounds depicted in Figure 5a.

In comparison with $\varepsilon$ the buoyancy Reynolds number shows an even wider distribution of halocline averages and highly variable latitude bin averages in which many extrema are not statistically significant as judged by the bootstrap confidence bounds. Mean $R e_{b}$ range from about $10^{3}$ to $10^{5}$ indicating vigorous mixing. Nevertheless, individual halocline $R_{b}$ were sometimes as small as 10-30, indicating an absence of "active" mixing (Stillinger et al., 1983; Rohr and Van Atta, 1987).

On a pragmatic level, variations in $R e_{b}=\varepsilon /\left(\nu N^{2}\right)$ are roughly indicative of variations in the eddy diffusivity, $K_{\rho}=\Gamma \varepsilon / N^{2}$. The reason is that the kinematic viscosity $\nu$ has a very limited range of variability as does the mixing efficiency $\Gamma=\Gamma(R i)$ following PB01 as long as $R i$ does not become too small. In a similar pragmatic vein, variations in $\varepsilon$ are roughly indicative of variations in the vertical turbulent salt flux, $J_{S}=10^{-3} \rho K_{\rho} \partial S / \partial z$ for practical salinity $S$ following PB01. Hence, Figure 5 indicates much larger variations in $K_{\rho}$ than in $J_{S}$ as a consequence of large variability in $N^{2}$. In the remainder of the paper we focus entirely on $\varepsilon$.
The wide distribution of halocline average $\varepsilon$ and $R e_{b}$ are predominantly due to tidal variability and, to a lesser degree, to fortnightly and longer term variability as shown in P99. It is important for the following that variations of $\varepsilon$ in the 1994/95 observations proved to be rather repeatable across tidal and fortnightly cycles (P99). Herein it is attempted to detect average spatial variations of variables with very large temporal variability. Local averages of $\varepsilon$ and $R e_{b}$ can thus easily be biased if they are formed from data distributed unevenly across the tidal and fortnightly cycles. Hence, the next step in the analysis is an examination of the distribution of the data.

\section{Data Distribution}

\section{a. Semidiurnal Tidal and Fortnightly Cycle}

In Figure 5, stretches along the river are labeled "1" for the area covered extensively in 1994/95 and " 3 " for the area of focus in 2001. Area "2" in between had sparser coverage than either area 1 or area 3 . The data coverage is shown in more detail in Figure 6 which depicts the data distribution as function of latitude, i.e. of distance along the river, and of time for the 2001 data, and additionally as function of semidiurnal tidal phase for all data. The semidiurnal tidal cycle was covered very well in area 1 , fairly well in area 3 , and not very well in area 2, which had an absence of measurements during late flood and early ebb. The area north of area 3 shows sparse data taken only during late flood and early ebb. The most northerly excursions in Figure 5 correspond to slack tides with weak mixing, hence to a low bias in $\varepsilon$. The observations from north of area 3 were taken for a purpose other than detecting spatial variations of mixing as briefly indicated above. Data from north of latitude $40.875^{\circ} \mathrm{N}$ are ignored in the remainder of this paper.

The distribution of the data within the semidiurnal tidal cycle and within the fortnightly cycle is made quantitative in Figure 7. The distribution of drops as function of $\Phi_{S D}$ in areas 1-3 is further subdivided into bins of the semidiurnal tidal amplitude at the Battery, $\zeta_{S D}$. (Note that $\zeta_{S D}$ in May 2001 is displayed in Figure 4c.) The overall data distribution as function of $\zeta_{S D}$ in areas $1-3$ is also shown (Figure $7 \mathrm{~d}$ ). The semidiurnal tidal cycle was evenly covered in area 1 while there was a bias toward late ebb and early flood in area 2 and, to a lesser degree in area 3 . Only area 1 had simultaneously even coverage across both $\Phi_{S D}$ and $\zeta_{S D}$.

\section{b. Lateral Variations}

After providing an overview of the temporal data distribution, the problem of variations across the river axis, 


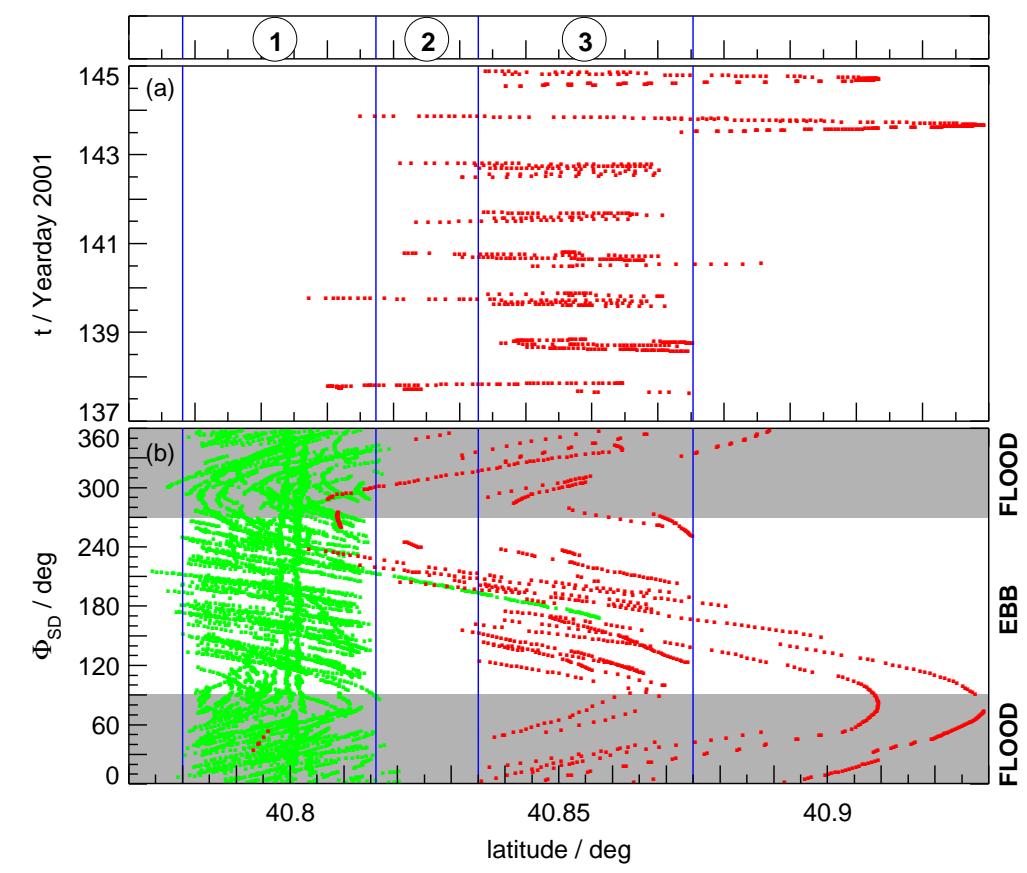

Figure 6. (a) Distribution of the 2001 data as function of latitude and time, and (b), distribution of the 2001 (dark dots) and 1994/95 data (light dots) as function of latitude and semidiurnal tidal phase. Latitude bands (areas) 1-3 from Figure 5 are marked on the top.

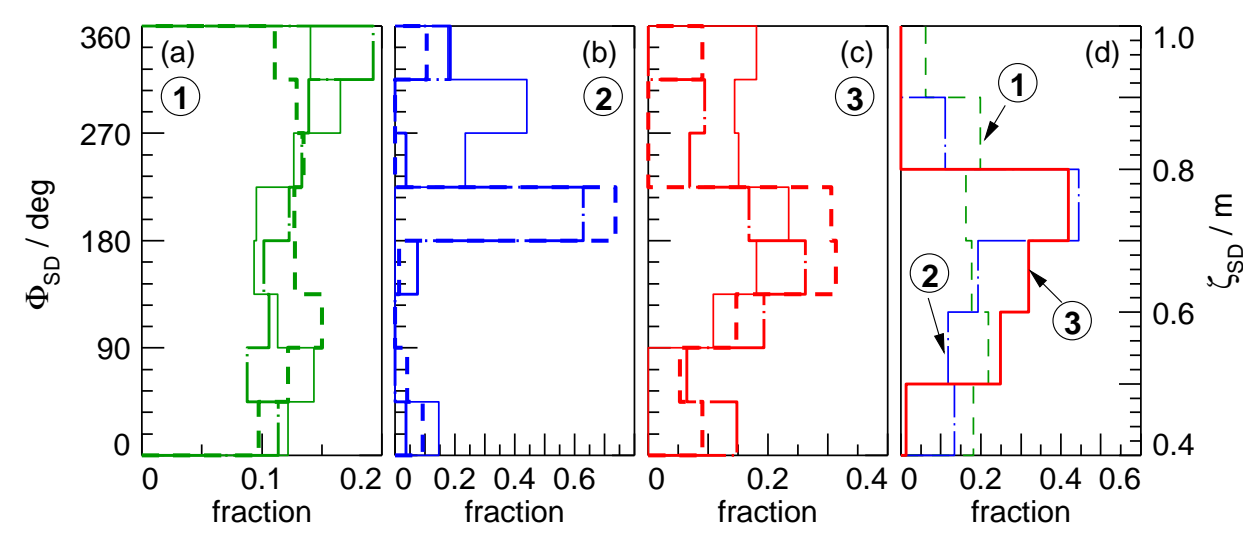

Figure 7. Data distribution as function of semidiurnal tidal phase, (a)-(c), and as function of semidiurnal tidal amplitude, (d), in areas 1-3 from Figure 5. In (a)-(c) the solid line is for data with semidiurnal tidal amplitude $\zeta_{S D}<0.6 \mathrm{~m}$; the dash-dotted line is for $0.6 \mathrm{~m}<\zeta_{S D}<0.7 \mathrm{~m}$, and the dashed line corresponds to $\zeta_{S D}>0.7 \mathrm{~m}$. 


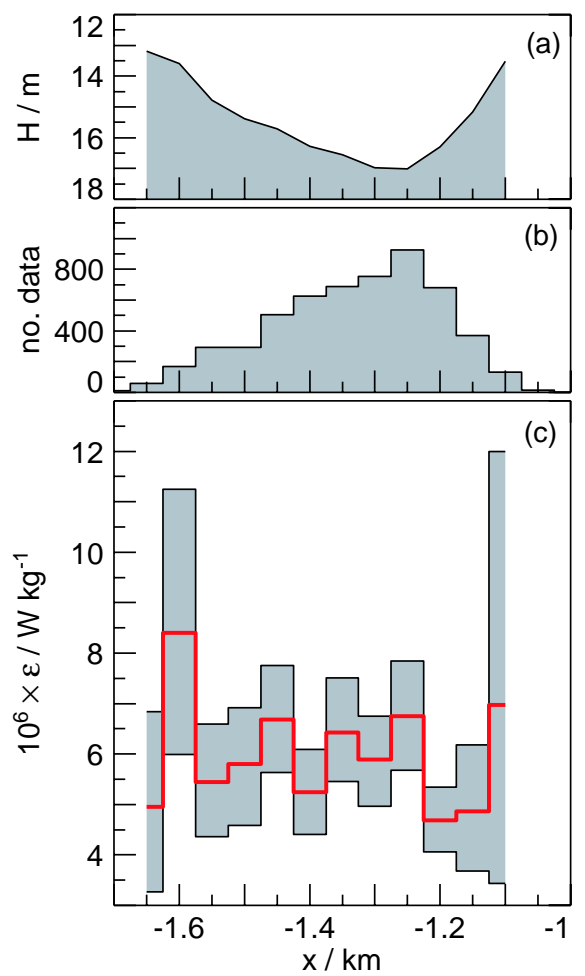

Figure 8. Area 1 data as function of across-river location. (a) average depth at locations of microstructure drops; (b) number of drops; (c) dissipation rate with $97 \%$ bootstrap confidence limits.

our $x$-coordinate, needs to be addressed. Most of the microstructure drops were taken from drifting vessels with limited control over the drift. Correspondingly, no deliberate attempt was made to observe mixing as function of the across-river distance. Rather, the strategy was to keep the vessels somewhat close to the thalweg and to restrict drops to depths greater than 10-12 m. With the quasi-free fall SWAMP profiler, usable microstructure data are obtained downward from about 3-3.5 m depth. The method is unsuitable for shallow areas.

The extensive 1994/95 data provide good coverage across the $\sim 500 \mathrm{~m}$ wide deep channel in area 1 (see Figures 1 and $6 \mathrm{~b}$ ). Figure $8 \mathrm{~d}$ demonstrates that the grand average of halocline averages of $\varepsilon$ was almost constant as function of $x$. Note that $\varepsilon$ is displayed on a linear scale. The underlying drops were most often taken near the thalweg, and the number of drops tapered off toward the shallower areas on either side of the river. The mean depth shown in Figure 8b is the average of all water depths at the time and place of drops taken, and is thus not the true mean depth. However, the asymmetric shape of the river bed is a true feature as seen by comparison with Figure $2 \mathrm{~d}$.

The absence of systematic lateral variations of $\varepsilon$ in the 1994/95 observations is taken as a justification of ignoring the $x$-location of drops in the entire 2001-94/95 data set. This approach is subject to the caveats that shallow areas are not covered and that substantial lateral flow occurs just south of the George Washington Bridge (Chant and Wilson, 1997).

\section{Enhanced Mixing Seaward of a Constriction}

The streamwise average of $\varepsilon$ depicted in Figure 5b lacks features other than a modest maximum south of the George Washington Bridge. Such enhanced mixing having been predicted by Chant and Wilson (2000) and related to hydraulically induced variations of the vertical flow structure, we proceed to examine if the observed maximum in $\varepsilon$ is significant in relation to systematic temporal, tidal and fortnightly, variability.

\section{a. Statistical Significance}

Figure 9 depicts the maximum of average $\varepsilon$ in the context of the streamwise variations of cross section. The straight average of $\varepsilon$ in bins of latitude shows an enhancement by a factor of about 3 south of the constriction relative to values at and north of the constriction, the minimum in $Q$. The bootstrap confidence bounds of the straight average indicates that the maximum in $\varepsilon$ is statistically significant. These statements have to be taken with a measure of caution, however, because of the bias in the data distribution with respect to the semidiurnal tidal and fortnightly cycles. Specifically, the cause of concern is the tidally uneven distribution of data in area 2 (Figure $7 \mathrm{~b}$ ) which, with a northern boundary at $40.835^{\circ} \mathrm{N}$ extends into the area of elevated $\varepsilon$ (Figure 9c).

However, the data distribution is biased toward late ebb and early flood, while ebb is the tidal phase for which Chant and Wilson (2000) predicted enhanced mixing. Thus one might expect the maximum in $\varepsilon$ from the straight average to be exaggerated. In order to further test this idea, the data are restratified into two areas north (upstream) and south (downstream) of the constriction, corresponding to regions $\beta$ and $\alpha$ in Figure 9 , respectively. The data are further restratified into four parts of the tidal cycle, late flood, early ebb, late ebb, and early flood. The corresponding averages all show enhanced mixing south of the constriction except for early flood. The latter is labeled "4" in Figure 9c, 

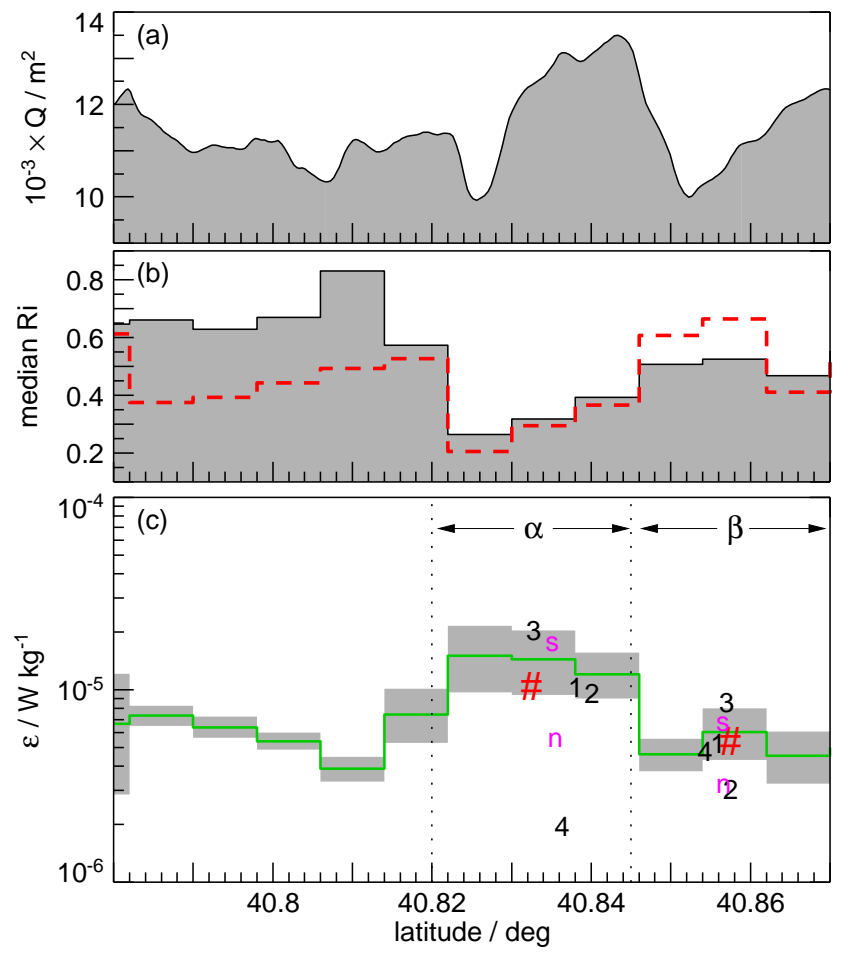

Figure 9. Flow observations in relationship to river cross section, $Q$. (a) Channel cross section. (b) Median of the gradient Richardson number, all data (shaded) and late ebb, only (dashed; $180^{\circ} \leq \Phi_{S D} \leq 270^{\circ}$ ). (c) Dissipation rate; straight average of all data: solid line with shaded confidence bounds; average in regions $\alpha$ and $\beta$ south and north of the constriction at the GWB in parts of the tidal cycle: 1 = late flood, 2 = early ebb, 3 = late ebb, $4=$ early flood; overall average from these tidal phase data in $\alpha$ and $\beta$ : pound sign; averages from neap tide $\left(\zeta_{S D} \leq 0.65 \mathrm{~m}\right)$ : "n", and spring tide $\left(\zeta_{S D}>0.65 \mathrm{~m}\right)$ : "s". while the other tidal phase are marked "1-3." These averages by tidal phase can be averaged again, resulting in different weights of individual data than in the straight average. The result still shows enhanced $\varepsilon$ south of the constriction by about a factor of 2 ("\#" in Figure 9c).

With respect to the fortnightly cycle, both areas 2 and 3 are biased toward spring tides, the bias being stronger in area 2 than in area 3 . In order to explore this issue further, the data were restratified as function of tidal amplitude, into $\zeta_{S D} \leq 0.65 \mathrm{~m}$ and $\zeta_{S D}>0.65 \mathrm{~m}$, marked "n" and "s," respectively, in Figure 9c. The enhancement of $\varepsilon$ south of the constriction by factors of 2-3 occurs in both cases. As expected, $\varepsilon$ was smaller during neap tides than during spring tides. In summary, we conclude that the enhanced mixing south of the minimum in river cross section at the George Washington Bridge is robust and significant with respect to temporal variability.

\section{b. Hydraulic Effects}

Chant and Wilson (2000) discuss how shear in the Hudson is enhanced near the constriction at the GWB during ebb tide, when the flow tends to be supercritical, but not during flood tide, when the flow is subcritical. In our notation, with $y$ as the streamwise coordinate, the slope of the halocline in two layer flow is given by

$$
\frac{\partial h_{1}}{\partial y}=\frac{F_{2}^{2} \frac{\partial H}{\partial y}+\left(g^{\prime} B\right)^{-1} \frac{\partial B}{\partial y}\left(v_{1}^{2}-v_{2}^{2}\right)}{\left(1-G^{2}\right)} .
$$

Here, $B(x, y)$ is the channel width, $g^{\prime}$ is reduced gravity, and $v_{1}$ and $v_{2}$ are the upper layer and lower layer streamwise velocities, respectively. With upper and lower thicknesses $h_{1}$ and $h_{2}$, the composite Froude number is $G=\sqrt{v_{1}^{2} g^{\prime} h_{1}+v_{2}^{2} g^{\prime} h_{2}}$, while $F_{2}$ is the corresponding lower layer Froude number. Equation (1) shows that, for supercritical flow, $G>1$, the thermocline is depressed at a constriction. Both layers flowing seaward, the upper layer faster than the lower layer, the flow in the latter has to accelerate because it encounters a reduced cross section. Hence the difference in layer velocities becomes smaller upon entering a constriction. The shear tendency can also be directly diagnosed by forming a $(y, z)$ vorticity equation from the steady state, inviscid, streamwise momentum equation and the spanwise, averaged continuity equation. A corrected version of their incorrect Equation (8) is

$$
\frac{\partial}{\partial y}\left(\frac{\partial v}{\partial z}\right)=\frac{1}{v B} \frac{\partial v}{\partial z}\left(u \frac{\partial B}{\partial y}+w \frac{\partial B}{\partial z}\right)+\frac{g}{v \rho} \frac{\partial \rho}{\partial y},
$$

with density $\rho$. Vertical shear is assumed to be independent of $z$, and $u$ and $w$ are assumed to be independent 
of $x$. Ebb flow implies $v<0$ as well as $\partial v / \partial z<0$, and $\partial B / \partial z>0$ always holds. As the flow enters the constriction, we have $\partial B / \partial y>0$, and the halocline is suppressed, such that $w<0$. Further, the density gradient reverses from its normal sign to $\partial \rho / \partial y>0$. Hence, $\partial / \partial y(\partial v / \partial z)$ becomes negative when the flow enters the constriction, and the magnitude of the shear decreases correspondingly. Similarly, after leaving the constriction, $\partial B / \partial y, w$ and $\partial \rho / \partial y$ all change sign relative to the above, and the shear magnitude increases correspondingly.

Without graphical illustration it is noted that the full 1994/95/2000 data show variations of $N^{2}$ which do not appear to be attributable to bathymetric variations, while the grand average squared shear exhibits minima near the two constrictions in the river cross section at latitudes $40.826^{\circ} \mathrm{N}$ and $40.852^{\circ} \mathrm{N}$. The resulting gradient Richardson number is represented in Figure $9 \mathrm{~b}$ by the median of its distribution, a simple and robust statistical measure. The median of $R i$ during late ebb shows maxima at or just south of both constrictions, and a decrease of median $R i$ extending south (seaward) of both constrictions over distances of $\gtrsim 2 \mathrm{~km}$. The median $R i$ of the complete data follows this pattern only at the more northerly, more significant constriction near the GWB. Our observations of shear and $R i$ thus qualitatively follow Chant and Wilson's (2000) diagnosis. Their prediction of enhanced mixing associated with reduced $R i$ seaward of the constriction at the GWB also holds true as seen in Figure 9 and as discussed in the previous subsection. The seaward decrease in median $R i$ in region $\alpha$ is paralleled by a maximum in $\varepsilon$. The tendencies in shear, $R i$ and $\varepsilon$ discussed above can also be clearly seen in synoptic streamwise ebb-tide sections shown in Figure 19 of P99 and, with the exception of $\varepsilon$, in Figures 4 and 5 of Chant and Wilson (2000).

\section{Conclusions}

Following is a brief summary of the principal findings.

1. The probed $15 \mathrm{~km}$ stretch of the Hudson River estuary was vigorously mixing with surprisingly small streamwise variations of average dissipation rates.

2. Mixing was enhanced by a factor of $2-3$ in a $2 \mathrm{~km}$ stretch seaward of the George Washington Bridge, where the river cross section narrows and where the river takes a modest bend. This feature is statistically significant but it carries limited weight within the average mixing along the entire $15 \mathrm{~km}$ stretch of the river.

3. The area of enhanced mixing is qualitatively consistent with the enhanced shear and reduced $R i$ predicted by inviscid hydraulic theory for supercritical ebb flow.

Some caveats need to be discussed. This study assumes spanwise variations of flow and mixing to be unimportant. This is consistent with the extensive 1994/95 data, but it has not been tested for the region of significant secondary, spanwise circulation south of the George Washington Bridge (Chant and Wilson, 1997). More importantly, studies of dye dispersion by Geyer, Chant and Houghton (personal communication 2001/02) indicate the importance of the interplay of secondary, spanwise circulation, vertical shear and mixing, and streamwise advection. In the region of dye injection north of the George Washington Bridge, strong vertical transport of the dye took place on the shoaling western side of the river where the halocline intersects with the bottom. It is not clear how much of this regime was captured in this study restricted to water depths exceeding about $10 \mathrm{~m}$. Our results hold for the deep channel around the thalweg.

The topic of hydraulics versus mixing deserves further discussion. Inviscid two-layer hydraulic theory results in qualitatively correct predictions concerning shear and mixing as outlined above. The theory cannot be applied quantitatively, however. Considering region $\alpha$ in Figure 9, for example, we see a continuing southward decrease of median $R i$ while the cross section also decreases, contrary to inviscid hydraulics represented by (1). The reason for this failure is the neglect of viscous effects. Hydraulic theory is largely built on energy considerations, with ordinary inviscid hydraulics neglecting dissipation. In reality, dissipation is a first order term in the energy balance of most flows in shallow waters. This fact was explicitly shown for the Hudson River in PB00.

Pratt (1986) discusses a hydraulic model of two layer flow with bottom stress for flow over a sill in a channel of constant width. The bottom friction leads to a shift of the controls and of the subcritical flow region downstream of the constriction. Such a shift, if applicable to the different geometry of the Hudson case, leads to better agreement between theory and observation than for the inviscid theory. Similarly, when bottom friction is included in the numerical model of Winters and Seim (2000) for exchange flow through a lateral constriction, the flow differs strongly from the case of no bottom fric- 
tion.

In summary, the Hudson River estuary exhibits both elements of a viscous-advective-diffusive balance, mixing intensely all along its thalweg, and simultaneously it displays a moderate hydraulic response to a moderate bathymetric feature. Models of the estuarine flow thus have to combine aspects of hydraulics and VAD concepts. Most critically, there is an urgent need for a turbulence closure that realistically parameterizes mixing in strongly stratified and strongly sheared flows with widely varying gradient Richardson numbers. One of the objectives of turbulence measurements, such as those presented herein, is to provide a data basis that allows highly discriminative tests of turbulence closures. Such tests based on turbulence observations have only begun to be explored and have yet to converge toward common conclusions (Simpson et al., 1996; Burchard et al., 1998; Stacey et al., 1999; Simpson et al., 2002; Peters et al., 2002).

Acknowledgments. The 1994/95 experiments were supported by the National Science Foundation. The Hudson River Foundation (HRF) provided funds for the 2001 field work but did not provide adequate support for the scientific analysis of the observations. The minimal overhead rate allowed by HRF was subsidized by the University of Miami Rosenstiel School. The New Jersey Marine Science Consortium, Dr. Michael Weinstein, Director, saved the experiment by letting us charter the R/V "Lionel A. Walford" on very short notice after another charter arrangement fell through three weeks before the cruise date. Dr. Weinstein's patience with University of Miami lawyers is especially appreciated. We are very grateful to Captain Jim Hughes and his mates Mike Danko and Mike Nuñez, who ran the "Walford" in a most professional manner, making our shipboard operations both successful and pleasant. Another big thank you goes to RSMAS Ocean Technology technicians Mark Graham and Robert Jones, who were as dedicated, skilled and effective as ever in cruise planning and preparation, logistics and shipboard measurements. Finally, the author thoroughly enjoyed being back to the great city of New York.

\section{References}

Burchard, H., O. Petersen, and T. P. Rippeth, Comparing the performance of the Mellor-Yamada and the $k-\varepsilon$ two-equation turbulence models, J. Geophys. Res., 103, 10,543 - 10,554, 1998.

Chant, R. J., and R. E. Wilson, Secondary circulation in a highly stratified estuary, J. Geophys. Res., 102, 23,207-23,215, 1997.

Chant, R. J., and R. E. Wilson, Internal hydraulics and mixing in a highly stratified estuary, J. Geophys. Res., 105, 14,215-14,222, 2000.

Efron, B., and G. Gong, A leisurely look at the bootstrap, the jackknife, and cross-validation, Am. Stat., 37, 36-48, 1983.

Geyer, W. R., and J. D. Smith, Shear instability in a highly stratified estuary, J. Phys. Oceanogr., 17, 1668-1679, 1987.

Geyer, W. R., J. H. Trowbridge, and M. M. Bowen, The dynamics of a partially mixed estuary, J. Phys. Oceanogr., 30, 2035-2048, 2000.

Hansen, D. V., and M. Rattray, Jr., Gravitational circulation in straits and estuaries, J. Mar. Res., 23, 104-122, 1965.

Hogg, H. M., G. N. Ivey, and K. B. Winters, Hydraulics and mixing in controlled exchange flows, J. Geophys. Res., 106, 959-, 2001.

Peters, H., Observations of stratified turbulent mixing in an estuary. Neap-to-spring variations during high river flow, Estuar. Coast. Shelf Sci., 45, 69-88, 1997.

Peters, H., Spatial and temporal variability of turbulent mixing in an estuary, J. Marine Res., 57, 805-845, 1999.

Peters, H., and R. Bokhorst, Microstructure observations of turbulent mixing in a partially mixed estuary. I: Dissipation rates, J. Phys. Oceanogr., 30, 1232-1244, 2000.

Peters, H., and R. Bokhorst, Microstructure observations of turbulent mixing in a partially mixed estuary. II: Salt flux and stress, J. Phys. Oceanogr., 31, 1105-1119, 2001.

Peters, H., M. C. Gregg, and T. B. Sanford, Detail and scaling of turbulent overturns in the Pacific Equatorial Undercurrent, J. Geophys. Res., 100, 18,34918,368, 1995a.

Peters, H., H. Baumert, and J. P. Jacob, Partially mixed estuaries: The Hudson River, in Marine Turbulence, Theories, Observations and Models, edited by H. Baumert, J. Simpson, and J. Sündermann, chap. 16, Cambridge University Press, Cambridge etc., 2002, accepted for publication.

Pratt, L. J., Hydraulic control of sill flow with bottom friction, J. Phys. Oceanogr., 16, 1970-1980, 1986.

Pritchard, D. W., Salinity distribution and circulation in the Chesapeake Bay estuarine system, J. Mar. Res., 11, 106-123, 1952. 
Pritchard, D. W., A study of the salt balance in a coastal plain estuary, J. Mar. Res., 13, 133-144, 1954.

Pritchard, D. W., The dynamic structure of a coastal plain estuary, J. Mar. Res., 15, 33-42, 1956.

Rattray, M., and D. V. Hansen, A similarity solution for the circulation in an estuary, J. Mar. Res., 20, 121-133, 1962.

Rohr, J. J., and C. W. Van Atta, Mixing efficiency in stably stratified growing turbulence, J. Geophys. Res., 92, 5481-5488, 1987.

Seim, H. E., and M. C. Gregg, Detailed observations of a naturally occurring shear instability, J. Geophys. Res., 99, 10,049-10,073, 1994.

Seim, H. E., and M. C. Gregg, The importance of aspiration and channel curvature in producing strong mixing over a sill, J. Geophys. Res., 102, 3451-3471, 1997.

Simpson, J. H., W. R. Crawford, T. P. Rippeth, A. R. Campbell, and J. V. S. Cheok, The vertical structure of turbulent dissipation in shelf seas, J. Phys. Oceanogr., 26, 1580-1590, 1996.

Simpson, J. H., H. Burchard, N. R. Fisher, and T. P. Rippeth, The semi-diurnal cycle of dissipation in a ROFI: Model-measurement comparisons, Cont. Shelf Res., 22, 1615-1628, 2002.

Stacey, M. T., S. G. Monismith, and J. R. Burau, Observations of turbulence in a partially stratified estuary, J. Phys. Oceanogr., 29, 1950-1970, 1999.

Stillinger, D. C., K. N. Helland, and W. C. Van Atta, Experiments on the transition of homogeneous turbulence to internal waves in a stratified fluid, J. Fluid Mech., 131, 91-122, 1983.

Stommel, H., and H. G. Farmer, Abrupt change in width in two layer open channel flow, J. Mar. Res., 11, 205-214, 1952.

Stommel, H., and H. G. Farmer, Control of salinity in an estuary by a transition, J. Mar. Res., 12, 13-20, 1953.

Thorpe, S. A., Turbulence and mixing in a Scottish loch, Philos. Trans. R. Soc. London A, 286, 125181, 1977.

Trowbridge, J. H., W. R. Geyer, M. M. Bowen, and A. J. Williams III, Near-bottom turbulence measurements in a partially mixed estuary: Turbulent energy balance, velocity structure, and along-channel momentum balance, J. Phys. Oceanogr., 29, 3056-3072, 1999.

Wesson, J. C., and M. C. Gregg, Mixing at Camarinal Sill in the Strait of Gibraltar, J. Geophys. Res., 99, 9847-9878, 1994.
Winters, K. B., and H. E. Seim, The role of dissipation and mixing in exchange flow through a contracting channel, J. Fluid Mech., 407, 265-290, 2000.

H. Peters, Rosenstiel School of Marine and Atmospheric Science, University of Miami, 4600 Rickenbacker Causeway, Miami, FL 33149-1098, USA

(hpeters@rsmas.miami.edu)

This preprint was prepared with AGU's LATEX macros v4, with the extension package 'AGU ${ }^{++}$' by P. W. Daly, version $1.6 \mathrm{~b}$ from 1999/08/19. 